\title{
Erratum to: Eartquake Vulnerability Level of Reconstructed Houses, Lesson Learned after Ten Years Java Eartquake 2006
}

Noor Cholis Idham ${ }^{1, *}$ and Munther Mohd $^{2}$

${ }^{1}$ Universitas Islam Indonesia, Indonesia

${ }^{2}$ Nablus University, Palestine

Original article:

SHS Web of Conferences 41, 06004 (2018), https://doi.org/10.1051/shsconf/20184106004

The title of the article should be replaced by the following text:

Earthquake Vulnerability Level of Reconstructed Houses, Lesson Learned after Ten Years Java Earthquake 2006 